\title{
A heterogeneidade no discurso do professor de língua portuguesa
}

Mary Neiva Surdi da Luz. E-mail: neivadaluz.@gmail.com Doutoranda em Letras, UFSM. Professora de Lingüística na Unochapecó.

Resumo: Este texto tem como objetivo analisar o discurso do professor de língua portuguesa sobre as suas práticas em sala de aula e suas relações com a Proposta Curricular de Santa Catarina, discutindo como esses sujeitos se identificam com as formações discursivas que representam a voz do Estado e se é possível identificar em seus discursos marcas do que é diferente no interior do mesmo, marcas da heterogeneidade constitutiva. Tomamos por base teórica a Análise de Discurso de Linha Francesa, nas noções de forma-sujeito, conceituadas a partir de Pêcheux (1995) e de formação discursiva heterogênea apresentada por Indursky (2002). Para construir a análise utilizamos como corpus recortes discursivos de falas professores de língua portuguesa.

Palavras-chave: análise de discurso; identificação; forma-sujeito; professores de língua portuguesa; formação discursiva.

\section{Introdução}

Quando se fala em ensino de língua portuguesa e em especial sobre a prática e formação de professores de língua portuguesa, algumas questões têm me inquietado tanto no papel de professora de língua portuguesa, de formadora de professores quanto de pesquisadora. As questões que venho perseguindo e que já têm sido discutidas nos trabalhos de autores como Coracini (2003), Eckert- Hoff (2002), Oliveira (2006) e Albuquerque (2006) dizem respeito à constituição da identidade do professor de língua: como o sujeito professor de língua portuguesa constrói sua identificação? Que discursos, que saberes e que práticas deixam marcas no seu dizer? Que sujeito é esse que ao mesmo tempo que tem o novo a sua frente não abandona a tradição?

Por isso, no ilusório desejo de controlar o meu ver e o meu dizer, tento me despir da posição de professora de língua portuguesa e me postar em uma posição de analista de discurso. Assim, pretendo neste texto, inaugural em minha formação em Análise de Discurso, adentrar o discurso do professor de língua portuguesa sobre as suas práticas em sala de aula e suas relações com a Proposta Curricular de Santa Catarina, discutindo como esses sujeitos se identificam com as formações discursivas que representam a voz do Estado e se é possível identificar em seus discursos marcas do que é diferente no interior do mesmo, marcas da heterogeneidade constitutiva.

De um eu particularizante, sinto agora a necessidade de passar a empregar um nós, por perceber que estas idéias que seguem não são minhas, já estavam aqui e em outros lugares a espera de um acontecimento que as fizessem emergir e produzir sentidos. Já me desfiz da ilusão de ser fonte e origem de meu dizer. Por isso passo a redigir em primeira pessoa do plural.

Para a elaboração deste artigo, partimos da idéia que o discurso do professor 
se inscreve na formação discursiva que representa, entre outros discursos, o discurso oficial do estado numa relação de identificação e, ao mesmo tempo, em uma relação de contra-identificação, instaurando a heterogeneidade marcada pela contradição e pela continuidade. Esse discurso pode ser afetado por saberes que vêm de outros lugares além daquele pro ou im posto pelo Estado, como os saberes da formação inicial e saberes construídos na própria prática de sala de aula.

Tomamos por base teórica a Análise do Discurso de Linha Francesa, doravante (AD), nas noções de forma-sujeito, conceituadas a partir de Pêcheux (1995) e de formação discursiva heterogênea na forma proposta por Indursky (2002) para compreender o discurso do sujeito professor de língua. Para construir a análise utilizamos como corpus seqüências discursivas de falas de professores de língua portuguesa em situação de entrevista semi-estruturada.

\section{Os sujeitos}

Os professores sujeitos deste trabalho são profissionais que atuam em escolas da rede estadual de ensino de Santa Catarina, em municípios que compõem a Gerência de Educação, Ciência e Tecnologia Chapecó/SC. Para a coleta de dados ${ }^{\text {[il }}$ foi utilizada a entrevista como ferramenta metodológica. Na entrevista, as perguntas foram feitas oralmente e as respostas, gravadas. A entrevista foi formada por um conjunto de questões, enunciadas em forma de pergunta, de modo organizado e sistematizado, tendo como objetivo alcançar determinadas informações e as informações que nos interessavam eram as em que o professor falava sobre o seu fazer em sala de aula e sobre o papel da Proposta Curricular de Santa Catarina na organização da aula de língua portuguesa. As entrevistas seguiram a técnica da entrevista focalizada que, segundo ANDRADE (1999), mesmo sem obedecer a uma estrutura formal, o entrevistador se utiliza de um roteiro com os principais tópicos relativos ao assunto. Para a realização das entrevistas foi realizado o contato inicial que, segundo RUDIO (1992), é de grande importância para motivar e preparar o informante, a fim de que suas respostas sejam realmente sinceras e adequadas. Todas as entrevistas foram gravadas nas escolas em que os professores atuam, em horários em que dispunham de tempo. Deve-se aqui registrar que esses professores mostraram-se bastante receptivos em participar de uma entrevista que tinha como o objetivo conhecer e compreender as concepções teórico-metodológicas que norteiam o trabalho do professor de língua portuguesa nos anos finais do ensino fundamental.

Para a realização deste trabalho, que tem por objetivo analisar o discurso do professor de língua portuguesa sobre as suas práticas em sala de aula e suas relações com a Proposta Curricular de Santa Catarina, foram selecionadas algumas seqüências discursivas de falas dos professores, as quais permitem vislumbrar as formas de identificação dos sujeitos. Dos dados registrados nas entrevistas, recortamos as informações que seguem para traçar um perfil de nossos sujeitos: 
A Professora $A$ atua no magistério há 22 anos, formou-se em Letras há pouco menos de uma década e em 2006 cursava mestrado em Literatura. Segundo ela, durante esse tempo que atua chegou a trabalhar em outras áreas, mas por pouco tempo, pois sempre preferiu atuar na área de língua portuguesa "porque é mais tranqüilo". Hoje ela tem sua carga horária de 40 horas semanais, mas atua de fato em $20 \mathrm{~h}$ e se explica dizendo que trabalha somente as $20 \mathrm{~h}$ por ter uma licença especial para poder cuidar de seu filho, um menino, com síndrome de Down.

- A Professora B concluiu seu curso superior há 30 anos. Fez sua faculdade em uma extensão da faculdade de Passo Fundo, isso foi em 1976. Era um grupo que formava professores para o primeiro grau e depois ela fez a complementação na Unochapecó-SC, em regime especial[ii], em Português e Inglês. Segundo ela, trabalhou quase todo o tempo com Português. Antes mesmo de ter concluído sua primeira graduação ela já atuava e hoje trabalha 40 horas semanais.

- A Professora C tem formação em Letras Português e se formou no ano de 1999. Quando começou a fazer o curso de Letras já atuava em sala de aula. Segundo ela, o primeiro ano em que trabalhou foi em 1978. Depois reiniciou em 1983 e "nunca mais parou". Hoje trabalha 40 horas semanais.

O Professor D concluiu sua graduação em 2001 e já dava aula antes de formado. Segundo ele, ao concluir o ensino fundamental, a oitava série, começou a trabalhar em sala de aula e por isso "Foi deixada muita coisa pra trás, mas cada ano venho trabalhando nisso". Eu comecei como substituto e a partir de então fui pra sala de aula". Ressalta ele que só passou a atuar na disciplina de língua portuguesa depois de concluir o ensino superior.

Pelo levantamento de dados, pode-se verificar que as graduações dos professores ocorreram em épocas distintas, entre 1976 e 2001, isso nos faz considerar o fato de que esses sujeitos tiveram orientadores teóricos e metodológicos diferenciados que marcam em seus discursos saberes advindos de diferentes FDs. Relacionam-se com saberes outros, mas se inscrevem na FD professor de língua. Para iniciar, levaremos em consideração aqui o trajeto que o ensino de línguas no Brasil percorreu e vem percorrendo, baseados na exposição de Soares (1998) e Eckert- Hoff (2002).

De acordo com Soares (1998), os anos de 1960 representam um marco no ensino de língua portuguesa. Com a democratização das escolas, as camadas populares têm garantido o espaço nos bancos escolares. A clientela atendida pelas escolas faz uso de outras variantes lingüísticas e não mais da variante dominada pela classe privilegiada da sociedade. No cenário sócio-político tem-se o desenvolvimento do capitalismo que atribui à escola a formação de recursos humanos. 
Eckert-Hoff (2002) acrescenta que na década de 70 os professores foram acusados de contribuir para o crescimento das desigualdades sociais. Essa década foi marcada por programas de formação de professores, numa perspectiva estruturalista. A formação era vista como treinamento e o professor um mero aplicador de métodos. Surgiram cursos de treinamento com a pretensão de habilitar o professor a "transmitir" os saberes.

Nos primeiros anos de 1980 novas teorias que chegavam das áreas das ciências lingüísticas provocaram mudanças significativas no ensino de língua portuguesa. Tem-se

[..] uma gramática que ultrapassa o nível da palavra e da frase e que traz nova orientação para o ensino da leitura e da produção de textos; sobretudo uma nova concepção de língua: uma concepção que vê a língua como enunciação, discurso, não apenas como comunicação, que, portanto, inclui as relações da língua com aqueles que a utilizam, com o contexto em que é utilizada, com as condições sociais e históricas de sua utilização.(SOARES, 1998, p.59).

É no final da década de 80 que se dão as bases para os pressupostos que vão orientar o ensino de língua portuguesa.

A partir da década de 90 , os cursos de formação surgiram de forma continuada e eram vistos como atualização, ou seja, a formação voltou-se para a relação entre os sujeitos. Esses curso tinham como objetivo principal ajudar os profissionais formados em décadas anteriores na apropriação desses novos conhecimentos que vão dar base aos documentos oficiais norteadores de ensino, tal como os Parâmetros Curriculares Nacionais e a Proposta Curricular de Santa Catarina.

Dado esse panorama, observa-se que os sujeitos desta pesquisa são frutos de diferentes orientações teóricas em seus cursos de formação inicial e isso reflete-se hoje na prática docente. Mas o que mais acaba chamando a atenção é o fato de que apesar de alguns sujeitos terem se formado há pouco tempo, ainda há problemas de atualização e coerência nos próprios cursos de formação inicial.

Isso foi constatado por Oliveira (2006) que analisou as grades curriculares dos cursos de Licenciatura em Letras. A autora investigou quais são os fundamentos teóricos e concepções de linguagem que subsidiam os estudos lingüísticos e argumenta com base em Pimenta (1999, apud Oliveira, 2006) que à construção de identidades dos docentes, não bastam os saberes oriundos da experiência, são também necessários os saberes científicos. O que se verificou é que a maioria das grades curriculares parte de uma concepção de língua como sistema estruturado; os conteúdos são dirigidos para estudos descritivos da língua padrão em seus níveis estruturais, aliados a concepções de gramática prescritiva e uma visão normativa de língua. A autora reflete que a construção da identidade do professor se faz em muito condicionada pelo seu processo formativo. As grades curriculares analisadas não permitem que o aluno construa uma identidade capaz de fazer um ensino de língua a partir de uma concepção de linguagem como interação. Oliveira (2006, on line ) conclui seu texto perguntando: "Afinal, como é possível a um professor, que não tem acesso em seu processo formativo a conteúdos que explicitem o modo enunciativo de 
funcionamento da linguagem, exercer uma prática que contemple esta concepção?"

\section{A Proposta Curricular de Santa Catarina: um pouco de sua história}

Além de compreender que os professores que entrevistamos têm trajetórias formativas diferenciadas e práticas que lhes são constitutivas, para a análise que propomos é imprescindível saber qual é o documento oficial norteador do ensino de língua portuguesa no estado de Santa Catarina e como se deu sua construção.

Em 1988, a Secretaria de Estado da Educação de Santa Catarina (SEE-SC) começou a se organizar para a criação da Proposta Curricular (PCSC) com o intuito de oferecer um instrumento para que os educadores aprofundassem seus conhecimentos e pudessem elevar a qualidade de ensino.

No mês de maio de 1988, em Blumenau-SC, aconteceu o primeiro Encontro de Componentes Curriculares quando teve início as discussões para uma possível Proposta Curricular. Investigou-se um suporte teórico-metodológico que garantisse uma ação interdisciplinar desde a pré-escola até o ensino médio. Em fevereiro de 1989, foi realizado um seminário interno na Coordenadoria de Ensino (CODEN) que estruturou e sistematizou as ações específicas da Proposta Curricular. Após, foram constituídos grupos de trabalho por disciplinas, com profissionais dos diferentes graus e modalidades de ensino da CODEN, observando a habilitação específica. Esse processo deu continuidade à superação das atividades individuais em favor de uma visão coletiva da totalidade.

A CODEN considerou esse processo árduo e problemático, tendo em vista a própria formação acadêmica e a vivência profissional que são alicerçadas numa visão de mundo fragmentada o que implica em conjunto de diversas práticas em uso em sala de aula. Como estratégia para desencadear um processo que passasse a envolver uma maior número de profissionais, foram realizados vários encontros em todo o estado. Em 1991 foi apresentada a versão preliminar que foi amplamente discutida e remodelada e em 1998 foi apresentada a versão definitiva que ainda vigora.

O eixo norteador da Proposta Curricular parte do princípio de que o homem está em um processo de constante contradição e transformação das próprias contradições. A educação é vista como inerente à sociedade e também passa pelo mesmo processo de contradicões e transformações.

A Proposta Curricular configura-se como um instrumento de trabalho colocado à disposição dos professores da rede estadual de Santa Catarina e pretende apresentar uma linha norteadora das atividades planejadas. Tem como objetivos que o ensino de qualidade promova a permanência do aluno na sala de aula; que haja a socialização do conhecimento e que o cidadão encontre um lugar social. A base teórica dessa proposta é sócio-histórica, ou histórico-social. Nesta perspectiva, a linguagem é vista como elemento que possibilita a interação humana, isto é fundamental na constituição do pensamento e da consciência. São as idéias de Vygotsky e Bakhtin que dão suporte a essa proposta. 
Vygotsky (apud PCSC, 1998) pesquisando as funções psicológicas complexas, memória voluntária, imaginação criativa e solução de problemas, hipotetizou o conceito de mediação. Para ele, o conceito de mediação é dirigido ao processo de desenvolvimento mental da criança e associado sempre à linguagem, sendo seu desenvolvimento um processo sócio-histórico. Para Vygotsky, a linguagem é um instrumento psicológico que age de forma mediadora no estágio precoce do pensamento e tem como resultado o pensamento verbal. Ela é social desde sua origem e funcionará como mediadora durante todos os processos de interação.

Mikhail Bakhtin (apud PCSC, 1998), filósofo da linguagem, vê a palavra como signo ideológico por excelência. Diz que a língua deve ser estudada como processo das relações sociais e tem características significativas: polifonia, polissemia, abertura e incompletude e dialogia. Segundo Bakhtin, as palavras vêm de outros sujeitos, outros tempos e outros lugares. A unidade lingüística primordial é a enunciação (processo de interação) e não o enunciado (produto); o discurso (ponte entre os sujeitos) se opõe à língua (código ou sistema).

A palavra precisa fazer sentido e tais sentidos dependem das condições de produção. Os sentidos possíveis são elaborados coletivamente: são meus e são do outro; constituem efeitos que podem ser obtidos no movimento polifônico (muitos falam na fala de cada um).

Assim como Vygotsky, Bakhtin também trabalhou por uma educação renovadora e sintonizada com seu tempo. Para eles, é preciso pensar o futuro como o presente estendido, como cada momento daqui para frente. E é a linguagem que marca todos esses processos.

\section{0 professor e sua identificação: princípios teóricos e análise de seqüências discursivas}

Depois de delinear quem são os sujeitos deste trabalho e qual o documento oficial que orienta o ensino de língua portuguesa em Santa Catarina, precisamos definir um aparato teórico que nos ajude a compreender como esse sujeito professor se posiciona sobre o seu fazer em sala e constitui sua identificação com a formação discursiva que representa a voz do estado de SC. Considerando que a relação que estabelecemos aqui é entre sujeito/história/discurso é na Análise do Discurso (AD) de linha francesa que buscamos aportes e suporte para a construção da análise.

Orlandi (2005) afirma que a AD trabalha com a língua no mundo, com as maneiras de significar e não com a língua enquanto sistema. Leva-se em conta o homem na sua história, considerando as condições de produção da linguagem e que a linguagem não é transparente. Objetiva-se compreender como um objeto simbólico produz sentidos, como ele está investido de significância para os sujeitos. Segundo a autora, "na Análise do Discurso, procura-se compreender a língua fazendo sentido, enquanto trabalho simbólico, parte do trabalho geral, constitutivo do homem e da sua história." (2005, p. 15).

Além disso, a AD ajuda a compreender como se dá a produção de sentidos, 
como os sujeitos articulam discursos que se relacionam às formações discursivas (FD) que, por sua vez, se inscrevem em formações ideológicas ( FI ). Pêcheux (1995) define a formação discursiva como aquilo que, numa formação ideológica, determina o que pode e o que deve ser dito. Assim, as palavras recebem seu sentido da formação discursiva na qual são produzidas. "Os indivíduos são interpelados em sujeitos-falantes (em sujeitos de seu discurso) pelas formações discursivas que representam "na linguagem" as formações ideológicas que lhes são correspondentes." (PÊCHEUX, 1995, p. 161).

De acordo com Orlandi (2005), na Análise do Discurso não vigora a noção psicológica de sujeito empiricamente coincidente consigo mesmo, ainda que o sujeito discursivo seja pensado como posição entre outras, "Não é uma forma de subjetividade mais um "lugar" que ocupa para ser sujeito do que diz."(p.49). Um bom exemplo para entender isso é perceber que os sujeitos são intercambiáveis, ou seja, um mesmo indivíduo assume-se como diferentes sujeitos em diferentes formações discursivas. Quando uma mulher fala da posição de mãe, ao questionar seu filho sobre o horário de chegada "Isso são horas?", o sentido do enunciado é construído a partir da posição de mãe assumida. “Podemos até dizer que não é a mãe falando, é a sua posição. Ela aí está sendo dita. E isso significa. Isso lhe dá a identidade. Identidade relativa a outras: por exemplo, na posição de professora, de atriz etc." (ORLANDI, 2005, p.49).

Pêcheux (1995) diz que o funcionamento da Ideologia em geral como interpelação dos indivíduos em sujeitos acontece por meio do complexo das formações ideológicas e dá a cada sujeito a sua realidade, enquanto sistema de evidências e de significações percebidas-aceitas-experimentadas (p.162). Ainda, que a interpelação do indivíduo em sujeito do seu discurso se efetua pela identificação (do sujeito) com a formação discursiva que o domina (isto é, na qual ele é constituído como sujeito).

Ao discutir os desdobramentos entre sujeito da enunciação e sujeito universal, Pêcheux afirma que é possível constatar que esse desdobramento pode assumir diferentes modalidades: identificação plena, contra-identificação e desidentificação.

\subsection{A identificação plena}

Na primeira modalidade há a superposição entre sujeito da enunciação e sujeito universal. Essa superposição revela uma identificação plena do sujeito do discurso com a forma-sujeito da FD que o afeta, tendo-se aí o discurso do bom sujeito, nas palavras de Pêcheux (1995).

Essa identificação plena aparece no discurso dos sujeitos professores de língua portuguesa quando em suas falas fazem referência explícita à concordância com as orientações teórico-metodológicas apresentadas pelo documento oficial Proposta Curricular de Santa Catarina (PCSC). Alguns exemplos nos ajudam a compreender melhor como isso acontece ${ }^{[i i i]}$ : 
(1)- E- E o documento da Proposta Curricular de Santa Catarina?

$P$ - Trabalhamos dentro dessa teoria sociointeracionista, levando em consideração o que o aluno já traz de casa, o conhecimento prévio; tudo isso a gente têm trabalhado na escola, têm cuidado, analisado. Só que, claro, a gente têm que estar sempre se preparando, se aprofundando, teorizando. Porque a prática vai se transformando e com isso também a teoria. Têm que andar juntas a teoria e a prática, tudo a gente não sabe ainda, mas está trabalhando dentro desse enfoque teórico da Proposta.

E- A Proposta, então, é um auxílio para as suas aulas?

P- Muito boa, muito boa. Acho que tem que ser por aí, interacionista mesmo. Acho que temos que deixar de lado as formas tradicionais de se trabalhar com os estudos. A Proposta Curricular de Santa Catarina é uma das melhores entre as que estão sendo trabalhadas no país. Ela está sendo mais evidenciada. (Professora A)

(2 )- Ajuda muito. Ela aborda a questão da reflexão que devemos ter quanto à nossa prática em sala de aula. Porque vê o aluno como sujeito, como ponto de partida para a nossa prática. Partindo do conhecimento que ele traz de casa, a gente aproveita aquele conhecimento do aluno e amplia, vai procurando não deixar de lado, mas ampliar o que ele traz e ali abordando a questão dentro da língua Portuguesa, para procurar fazer com que ele guarde, tenha uma visão de mundo. (Professora $C$ )

(3) P- Eu já sou professora há mais de 35 anos, então eu acompanhei a Proposta Curricular desde a implantação, todos os estudos feitos, da simulação. Eu tenho um bom conhecimento sobre a Proposta.

E- Foram feitos muitos cursos até chegar ao documento atual?

P- Foram muitos e tiveram várias etapas de implantação, depois ficou um tempo esquecido, sem ter um reforço de tudo, uma cobrança para estarem vendo de novo.

E- Essa Proposta final, ajuda nas suas aulas?

P- Ela faz com que a gente esteja sempre repensando a prática. A própria proposta ela sugere isso que a gente faça sempre este questionamento: "o que eu estou fazendo?", "o que vai servir isto pra mim?" "e o que eu posso modificar?" A participação, a Proposta Curricular exige muito que se trabalhe a participação. (Professora $B$ )

Nas seqüências discursivas acima, localizamos processos de identificação plena da forma-sujeito com a FD que representa o discurso do Estado. Em (1), o sujeito emprega o verbo trabalhamos na primeira pessoa plural, com um nós inclusivo (com elipse do pronome pessoal), causando esse efeito de identificação e inclusão que é reforçado pelo emprego do pronome demonstrativo dessa, o qual retoma o que foi enunciado pelo seu entrevistador na pergunta. Além disso, o sujeito classifica a PCSC como uma das melhores entre as que estão sendo trabalhadas pelo país, em uma explícita adjetivação positiva.

Em (2), novamente temos uma identificação plena que é marcada nas palavras iniciais da resposta da professora quando ela diz Ajuda muito. Ocorre nessa resposta uma afirmação, confirmação de identificação, reforçada pelo emprego do operador (advérbio de intensidade) muito. Note-se que sua fala não teria o mesmo efeito de sentido sem o uso de muito.

Para melhor evidenciar as marcas lingüístico-discursivas presentes nas falas dos professores podemos nessa análise trazer à tona as constribuições de Oswald Ducrot sobre a noção de escala argumentativa ${ }^{[i v]}$. Segundo Ducrot (apud Guimarães,1995), há na estrutura semântica das línguas as marcas de relação argumentativa, ou seja, há uma caráter escalar dos argumentos. "Há entre os argumentos uma relação de menor e de maior força para uma certa conclusão." 
(GUIMARÃES, 1995, p. 50). Em uma escala, teríamos:

Se fizermos uma transição da noção de escalas argumentativas, que é uma noção aplicada à semântica enunciativa, para a análise do discurso podemos dizer que cada ponto da escala eqüivale a uma forma de identificação. Assim, essa escala iria de uma identificação plena (ajuda muito), passando por um contra-identificação (ajuda pouco) até chegar a uma desidentificação (não ajuda). Diríamos então que, em vez de indicar uma orientação argumentativa para uma conclusão $r$, o emprego de alguns operadores ajudam a marcar as posições-sujeito em uma dada situação discursiva.

O uso das formas pronominais também nos dão pistas da identificação plena. Em Ela aborda a questão da reflexão que devemos ter quanto à nossa prática em sala de aula, podemos perceber que ao falar na proposta emprega o pronome pessoal ela e na seqüência introduz o verbo flexionado em primeira pessoa de plural e um pronome também de primeira pessoa. Tem-se aí um efeito de inclusão: ela (PCSC) mais eu (professora ou classe de) igual a nós: um sujeito com identidade coletiva e em pleno acordo.

Em (3), vemos que o sujeito professor de língua portuguesa ao dizer: "Eu já sou professora há mais de 35 anos, então eu acompanhei a Proposta Curricular desde a implantação, todos os estudos feitos, da simulação. Eu tenho um bom conhecimento sobre a Proposta.", subjetiva-se pelo emprego do pronome eu que marca o sujeito discursivo a quem se imputa o dizer. Tem-se um sujeito que afirma que já é professor há mais de 35 anos e que acompanhou a implantação de todo o processo. E isso parece atribuir autoridade ao seu dizer. A identificação plena é marcada quando o sujeito afirma ter um bom conhecimento sobre a proposta. Assim, nessa seqüência, parece ficar evidente um "orgulho" do ser professor e de ter acompanhado a construção do documento. Pois, além de o professor poder ter contribuído devido a sua vasta experiência, ele também sentiu-se valorizado ao poder ter acompanhado o elaboração da PCSC, de ter participado. Isso é reafirmado quando diz: "A participação, a Proposta Curricular exige muito que se trabalhe a participação." Precisamos aqui retomar a informação de que o documento da PCSC foi construído com uma metodologia participativa em que os professores atuaram constantemente e em um processo de interação dialógica em que os processos foram mediados pela 
linguagem.

Apesar disso, não podemos ignorar que Pêcheux (1990) aponta que todo discurso marca a possibilidade de uma desestruturação-reestruturação, assim, "não há identificação plena bem sucedida, isto é, ligação sócio-histórica que não seja afetada de uma maneira ou de outra, por uma "infelicidade" no sentido performativo do termo." (p. 56).

\subsection{A contra-identificação}

Para Pêcheux (1995), a segunda modalidade de identificação caracteriza o mau sujeito, pois o discurso do sujeito da enunciação se volta contra o sujeito universal por meio de uma tomada de posição. O sujeito se contra-identifica com a formação discursiva que lhe é imposta. Indursky (2002) afirma que esta tensão entre a plena identificação com os saberes da FD e a contra-identificação com os mesmos saberes ocorre no interior da FD, o sujeito do discurso questiona saberes pertencente à FD em que ele se inscreve. Não se tendo mais uma identificação plena, abre-se espaço para uma superposição incompleta que permite a instauração da diferença e da dúvida que são responsáveis pela contradição no âmbito dos saberes da FD. "Ou seja: esta segunda modalidade traz para o interior da FD o discurso-outro, a alteridade, e isto resulta em uma FD heterogênea." (p.06).

Em suas falas, os professores revelam essa contrariedade:

(4) Olha, tem a parte boa e tem a parte ruim. O que ela traz pra gente são alguns momentos que têm sentido, só que a gente para lá na frente pela dificuldade de você ter acesso a certas coisas, objetos de trabalho ou material de pesquisa. A Proposta é boa, mas nós aqui enfrentamos a dificuldade de não ter o material adequado para fazer tudo o que diz dentro da Proposta. Quando você estuda, você está lendo com os colegas você pensa "agora vou fazer um trabalho diferente", mas de repente você vai vendo que não tem subsídios para continuar esse trabalho, tem a questão financeira, a dificuldade de adquirir o material, a escola não tem, o Estado não manda, tudo isso acaba atrapalhando o trabalho e a gente acaba entrando na rotina, é livro, é caderno e é quadro. (Professora D)

Em (4), temos um seqüência discursiva com marcas lingüísticas bastante explícitas de contra-identificação. Ao dizer: "Olha, tem a parte boa e tem a parte ruim..", o sujeito marca a instauração da diferença pelo emprego dos antônimos bom e ruim aplicados às partes de um mesmo documento/objeto. É a possibilidade de contra-identificar-se que permite que o sujeito possa abrir espaço para a aparente contradição e em uma relação metonímica fazer referências às partes do documento e não comprometer o todo. Ao mesmo tempo que se identifica com alguns saberes (partes do todo), questiona e pode refutar outros (outras partes). Assim, o sujeito garante o não abando por completo dos preceitos da FD que representa a voz do Estado.

Em A Proposta é boa, mas nós aqui enfrentamos a dificuldade de não ter o material adequado para fazer tudo o que diz dentro da Proposta, é importante observar 
que o uso da conjunção mas marca novamente uma regularidade. É boa mas tem partes problemáticas que são listadas na seqüência. Com essa estratégia, o sujeito novamente revela sua constra-identificação: concorda com algumas partes e discorda de outras partes. Se não houvesse qualquer concordância, ele seria um sujeito desidentificado.

Ao introduzir o pronome nós e expressão pronominal a gente, o sujeito, por meio de uma estratégia lingüística de inclusão, insere o outro em seu dizer. Esse nós/ a gente abarca os outros sujeitos da instituição escolar: os outros professores, os funcionários, enfim, os colegas. Com essa estratégia, imputa-se ao nós/ a gente a responsabilidade pelo dizer. Não é o eu singularizante que diz, é um nós coletivo que compartilha esse dizer e por ele se responsabiliza, já estão todos sob o teto de uma mesma formação discursiva.

Devemos observar que a fala desse professor vem marcada por um discurso de vitimização. Ou seja, o professor é apresentado como um sofredor que enfrenta muitas dificuldades, que não tem os materiais adequados, que tem problemas salariais e que entra em uma rotina. Assim, o Estado é responsabilizado pela contraidentificação.

Eckert-Hoff (2002, p. 113), resume as idéias acima com as seguintes palavras:

Ao se posicionar, o sujeito-professor tece discursos que emanam não apenas de seu percurso de formação, como também de diferentes situações da vida profissional, evidenciando pontos de identificação que marcam a heterogeneidade desse dizer. Sua identificação ou contra-identificação com esse, ou aquele fazer, constitui o movimento de sua formação.

\subsection{E a desidentificação?}

Além da identificação plena e da contra-identificação, Pêcheux (1995) acrescenta uma terceira modalidade, na qual o sujeito ao desidentificar-se de uma formação discursiva, desloca sua identificação para outra formação discursiva., tendo-se assim um mau-sujeito.

Nas entrevistas realizadas com os professores de língua portuguesa, não conseguimos localizar seqüências discursivas que marcassem uma forma-sujeito desidentificada. $\mathrm{E}$ isso parece acontecer porque a desidentificação do professor com a formação discursiva que representa a voz do Estado, que é aquela que rege e regula o sistema de ensino, levaria o professor a deixar de ser professor desse contexto em que está inserido, pois vimos durante as análise que o professor tem orgulho de sê-lo e de ajudar o Estado a construir um documento, mesmo que em alguns momentos explicite que o Estado é também o responsável pela contra-identificação.

Podemos assim dizer que a desidentificação não foi localizada porque esses professores já desidentificados não aceitariam nem mesmo a participação nas entrevistas em que teriam de falar de si, falar de sua prática, de sua relação como o Estado, pois 
incorporação de uma multiplicidade de outros fazeres e dizeres que são dissimulados, o que é evidenciado pelos deslizes de posição-sujeito. (ECKERTHOFF, 2002, p.113)

\section{Conclusões possíveis}

Ao fazer esse exercício de escuta para descobrir quais são as formas de identificação do professor de língua portuguesa, percebemos que temos sujeitos que marcam suas posições em relação ao papel do estado: seja pela concordância plena ou parcial.

Assim temos o sujeito com identificação plena, que embora carregue os traços de infelicidade, identifica-se com a formação discursiva de ser professor de língua portuguesa no estado de Santa Catarina, que determina o que pode e o que dever ser dito em relação ao ensino de língua portuguesa. Podemos pressupor que o sujeito no contexto imediato de entrevista sente-se ideologicamente interpelado a responder, a produzir (inconscientemente) um efeito de unidade no seu dizer sobre a profissão e, portanto, homogeiniza sua fala no sentido de produzir um efeito de identificação plena com a FD onde está prioritariamente inscrito.

Há também a contra-identificação que emerge nos discursos daqueles que apontam (conscientemente ou não) suas queixas e discordâncias em relação à FD em que estão inscritos enquanto professores de língua portuguesa e funcionários do Estado de Santa Catarina. Isso é possível porque partimos da noção que a formação discursiva é heterogênea e pode assim comportam sujeitos e efeitos heterogêneos.

Não temos os maus sujeitos, os sujeitos desidentificados, aqueles que já não se inscrevem mais na formação discursiva de ser professor de língua portuguesa. Ao retomar o perfil dos sujeitos-professores, podemos lá ver que eles são professores há um bom tempo e só o são ainda porque mantém alguma identificação com o ser professor de língua portuguesa. Aqueles que não conseguem mais se identificar, traçam outros caminhos e mudam de profissão.

Ao discutir os processos de identificação de professores de língua materna, Coracini (2003) aponta que a identificação do sujeito se forma ao longo do tempo, por meio de processos inconscientes. Ela permanece sempre incompleta, sempre em processo. Toda a identificação só acontece porque encontra alguma resposta no interior do sujeito "é preciso entendê-la não como resultado de uma plenitude ou da completude ilusória de um sujeito indiviso, mas de uma "falta": falta de inteireza que procuramos preencher sem jamais conseguir, a partir de nosso exterior, pelas formas através das quais nós imaginamos ser vistos por outros: sei quem sou em relação com o outro que eu não posso ser" (p.243). A autora chama atenção para a hipótese de que o professor é atravessado por uma multiplicidade de vozes que tornam sua identidade complexa, heterogênea e em mudanças, sendo que só é possível capturar momentos de identificação. Assim, neste trabalho conseguimos capturar momentos 
em que o professor se identifica plenamente e outros em que se contra-identifica. Mas sendo sempre professor.

\section{Referências}

ALBUQUERQUE, Eliana Borges Correia de. Mudanças didáticas e pedagógicas no ensino de língua portuguesa. Belo Horizonte: Autêntica, 2006.

ANDRADE, Maria Margarida de. Introdução à metodologia do trabalho científico: elaboração e trabalhos de graduação. São Paulo: Ática, 1999.

CORACINI, Maria José. Subjetividade e identidade do (a) professor de português. In: CORACINI, Maria José (org.). Identidade e discurso. Campinas: Editora da Unicamp; Chapecó: Argos Editora Universitária. 2003.

ECKERT-HOFF, Beatriz Maria. O dizer da prática na formação do professor. Chapecó: Argos, 2002

GUIMARÃES, Eduardo. Os limites do sentido. Campinas: Pontes, 1995.

HALL, Stuart. A identidade cultural na pós-modernidade. Rio de Janeiro: DP\&A, 2002.

INDURSKY, Freda. A noção de sujeito em Análise do Discurso: do desdobramento à fragmentação. Texto apresentado no GT de Análise do Discurso, durante o XV Encontro da ANPOLL. Niterói, 2000 - publicado no CD-Rom Síntese 2, Seção de Análise do Discurso, ANPOLL, Porto Alegre, 2002.

PÊCHEUX, Michel. Semântica e discurso: uma crítica à afirmação do óbvio. Campinas: FUCAMP - Fundação de Desenvolvimento da UNICAMP, 1995.

O discurso: estrutura ou acontecimento. Campinas: Pontes, 1990.

OLIVEIRA, Maria Bernardete Fernandes de Oliveira. Revisitando a formação de professores de língua materna: teoria, prática e construção de identidades. Linguagem em (Dis)curso. Tubarão. Vol 6, №1, jan/abr 2006. Disponível em: $<$ http://unisul.br/paginas/ensino/pos/linguagem/0601/06.htm> . Acesso em 14/06/2006.

ORLANDI, Eni. Análise do discurso: princípios e procedimentos. São Paulo: Pontes, 2005.

RUDIO, Franz Victor. Introdução ao projeto de pesquisa científica. Petrópolis: Vozes, 1992

SANTA CATARINA. SECRETARIA DE ESTADO DA EDUCAÇÃO E DO DESPORTO.

Proposta curricular de Santa Catarina: educação infantil ensino fundamental e ensino médio (disciplinas curriculares). Florianópolis: COGEN, 1998.

SOARES. Magda B. Concepções de linguagem e o ensino da língua portuguesa. In: BASTOS, Neusa (org.). Língua portuguesa: história, perspectivas, ensino. São Paulo:Educ, 1998.

TRAVAGLIA, Luiz Carlos. Gramática e interação. São Paulo: Cortez, 1996.

[i]

Dados coletados para a execução do projeto “Concepções teórico-metodológicas que norteiam o ensino de línguas", realizada pelo Grupo de Pesquisa Estudos Lingüísticos e Literários, da Unochapecó, SC, no ano de 2006, financiada pelo Balcão de Projetos com recursos da Unochapecó e bolsa de pesquisa do Artigo 170- lei estadual- SC. Os dados coletados pelo projeto foram cedidos ao nosso trabalho que propõe analisar o discurso do professor de língua portuguesa sobre as suas práticas em sala de aula e suas relações com a Proposta Curricular de Santa Catarina,

[ii] Regime especial: designa o regime de oferta do curso, este é oferecido durante os finais de semana e com semanas intensivas no período de férias escolares das diversas redes.

${ }^{[i i i]}$ E: entrevistador 
P: professor (a)

[iv] Para este trabalho interessa-nos tão somente essa noção de escala argumentativa. As demais noções propostas por Ducrot em seus diversos trabalhos, não serão aqui usadas ou apresentadas. 